\title{
Workplace Mediation in Ireland: Bridging the Research-Practice Gap
}

\section{Deirdre Curran}

\begin{abstract}
The purpose of this article is to present a case for the importance of research in informing mediation practice specifically in the context of the management of workplace conflict in Ireland. The position of mediation within the broader dispute-resolution framework is clarified at the outset and the core mediation process is described. The increasing use of mediation in Ireland and the changing institutional context within which it is conducted are discussed. The importance of research is stressed along with crucial methodological challenges. The paucity of workplace mediation research in Ireland is highlighted and the preliminary findings of an on-going research project are presented. The article concludes that more research into workplace mediation in Ireland is needed to inform practice in this area and to improve external perception of the legitimacy of mediation as a dispute resolution process.
\end{abstract}

\section{Keywords}

Mediation, research-practice, workplace

\section{Mediation}

Mediation is a process of dispute resolution in which a neutral third party [the mediator] uses a structured process to help disputing parties to address their conflict in whatever way they deem appropriate with a view to resolving the issues. The mediator uses his/her expertise to manage the process. However, the issues and the outcomes belong to the disputants.

The process of mediation can be employed to resolve conflict in a variety of settings from international disputes between countries, to commercial disputes between companies, to conflict at the level of; communities, workplaces, families and/or individuals. The context in which this article is couched is the resolution of disputes within the workplace. Many conflict triggers occur in the workplace:

It may be that two workers simply don't get on; or that an individual has a grievance against their manager.

Conflict may take the form of rivaly between teams; or it may be apparent by the lack of trust and cooperation between large groups of employees and management. (ACAS Advisory Booklet) 
The types of workplace disputes that form the basis of the research referred to in this article, fall into one of two categories. The first is interpersonal conflict between individuals or small groups that results in a breakdown of working relationships. The second is conflict arising from an alleged breach of equality law. In other words, one party claims to have been discriminated against by the other party under the provisions of Irish equality law. In some cases, disputes presenting in the second category actually emerge as more symbolic of the first category, the presenting issue not always being the real issue.

Whatever the presenting issue, mediation is one of a number of dispute resolution processes as illustrated in Diagram 1 below. Adapted from Schaefer (2013) this continuum distinguishes mediation from other dispute resolution processes across the three parameters of, the degree of self-determination afforded to the disputants, the reduced cost of resolution compared to the extreme of litigation, and the relative informality of the process.

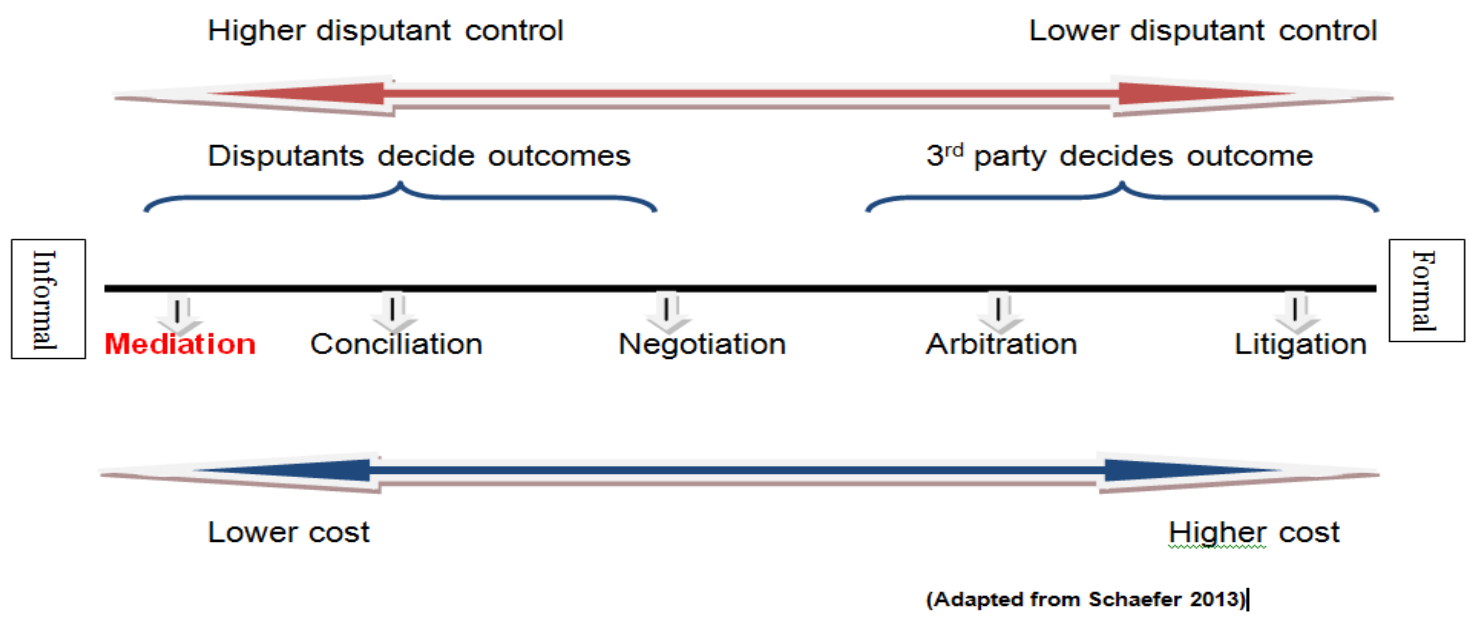

DIAGRAM 1: DISPUTE RESOLUTION CONTINUUM

A review of the international literature reveals a degree of variation in how mediation is practiced, as illustrated in multiple style descriptors such as facilitative, evaluative, transformative, and narrative. Wall and Dunne (2012: 226/7) in their review of a decade of mediation literature identified about twenty-four classifications of mediator styles ('strategies'), and 'approximately one hundred behaviours ('techniques') that mediators chose from during the course of a mediation.

No matter which techniques and strategies mediators utilise, there is an assumed commonality in the core process of mediation as illustrated in Diagram 2 below. This mediation process will often be preceded by 'pre-mediation' to ensure that the parties are clear about what is involved and that they are engaging with the process voluntarily. Caucusing is also commonly used throughout the process if and when the mediator feels there is reason to speak to either party separately. Representatives may/may not be allowed to be present during the mediation and, if present, their role may be circumscribed by the mediator. 


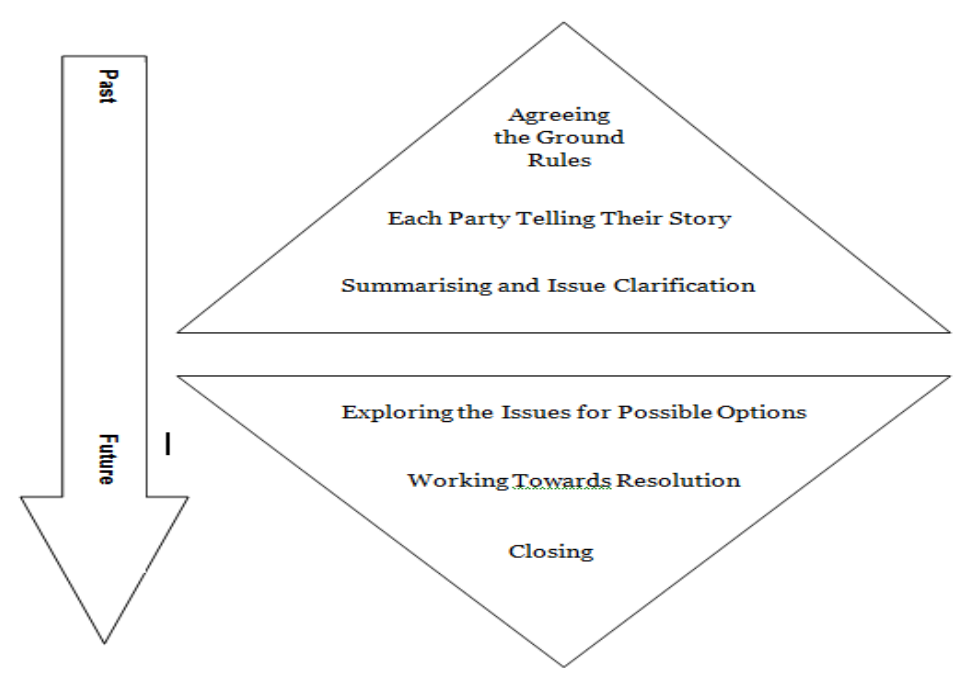

DIAGRAM 2: THE MEDIATION PROCESS

\section{Workplace conflict}

The pluralist perspective holds that workplace conflict is inevitable, although not necessarily a bad thing (Fox, 1973, Salamon, 2000, Rose, 2001). The critical element is how it is managed. Effective management of conflict can lead to positive outcomes such as creativity, improved decision making and better employee relations.

However, experience tells us that workplace conflict is often handled poorly, or not at all, leading to destructive outcomes for individuals and for organisations. Katz and Flynn concluded, based on their review of the literature, that 'workplace conflict is a significant variable in workplace productivity, effectiveness, and overall success.' (2013: 396) Estimating the cost of workplace conflict is extremely difficult and can include employee absence and turnover, management time, low morale, reduced performance, damaged reputation and the cost of legal proceedings. Perhaps the most worrying cost of workplace conflict, which was reported to the author frequently during the course of her research, is the psychological damage caused to individuals leaving them incapable of achieving their potential both at work and in their personal lives.

Kenny (2014) in her review of the literature cited estimated costs of workplace conflict ranging from \$35.4billion annually in the US to $f_{2}^{24 m i l l i o n}$ in the UK. This would suggest significant potential benefit can be accrued from effective conflict resolution.

\section{Increasing use of mediation}

Mediation is becoming increasingly popular as a mechanism for dispute resolution in Ireland. A recent Industrial Relations News (IRN) article highlighted this trend.

Mediation is being strongly promoted by the legal and political establishment, along with other forms of alternative dispute resolution. The signs are that it is catching on as a means of addressing conflict in the workplace and some of its progress may be down in part to considerations of cost and administrative convenience. (IRN2014) 
In the public arena in Ireland, mediation is offered by the Workplace Relations Commission to address both individual/small group disputes and complaints of discrimination. In the private arena, the professional association of mediation practitioners in Ireland, the Mediators Institute of Ireland (MII), currently has 700 members and has accredited 35 mediation training programmes across the country. Of the 700 mediators registered with the MII, 180 claim to 'specialize' in workplace disputes, although it is reasonable to assume that many of the 'generalists' will mediate workplace disputes if requested. All of the accredited training programmes, bar two, either specialize in or cover workplace mediation.

The Mediation Bill is scheduled for enactment in 2014. The aim of the Bill is to encourage and facilitate the use of mediation in resolving civil, commercial and family disputes. It seeks to provide an effective and efficient alternative to litigation by reducing legal costs and speeding up the resolution of disputes. On publication of the Bill the Irish Minister for Justice, Equality and Defence said,

The general objective of the Bill is to promote mediation as a viable, effective and efficient alternative to court proceedings thereby reducing legal costs, speeding up the resolution of disputes and relieving the stress involved in court proceedings. I am anxious to ensure that individuals and companies engaged in a dispute regard resolution of their dispute through mediation as preferable to court litigation.

(http://www.justice.ie/en/JELR/Pages/PR12000041).

In a separate legal development, the most recent draft of the Irish Workplace Relations Bill, designed to underpin provisions for the resolution, mediation and adjudication of disputes within the employment relationship, makes 42 references to mediation as a mechanism for dispute resolution.

...the Director General may, where he or she is of the opinion that a complaint or dispute is capable of being resolved by mediation, refer the dispute for mediation by a mediation officer. The Director General shall not refer a complaint or dispute for mediation to a mediation officer under paragraph (a) if either of the parties to the complaint or dispute objects to its being so referred. Workplace Relations Bill Section 39 (1) (a) and (b)

Mediation Officers will be appointed for the purposes of the Act and mediated agreements will be enforceable in Court.

The terms of a resolution consequent upon a mediation conference under this section shall be binding on the parties and if either party contravenes any such term, the contravention shall be actionable in any court of competent jurisdiction. Workplace Relations Bill Section 39 (6)

Clearly the legal and institutional context for mediation is changing in a way that will encourage the increasing use of mediation as a mechanism for dispute resolution. 


\section{Why is research important?}

Lang (2000) in his article about 'reflective practice' argued the case for the importance of theory in informing practice.

I realized that without understanding the underlying theoretical principles of practice, we are merely skilled mechanics trying out one tool after another without understanding what tool would be appropriate to the task. www.mediate.com//articles/reflect.cfm

Theory both triggers, and emerges from, research. It allows us to understand, explain and in some cases predict. Once a theory is established it can be tested and confirmed using research methods such as systematic observation, experimentation, and laboratory studies. For example, Diagram 1 (p3) represents a theoretical framework for how the process of mediation works. It is often used as a tool for training mediators and as a result many mediators use it as a framework for their practice. However, is this how the process of mediation actually works? Should it be? The framework needs to be rigorously tested through research to either confirm its validity or make progress towards a more viable alternative.

Theory provides both a foundation for our work and a way to understand the nature of the process we are managing. It gives the practitioner a foundation upon which to base an assessment of a conflict situation and to design an appropriate intervention. (Lang, 2000 ibid.)

Research can be defined as 'a systematic process of critical inquiry leading to valid propositions and conclusions that are communicated to interested others.' (McLeod, 2003).

The desire to conduct research comes from an innate human propensity to wonder and a desire to know. The body of existing knowledge about workplace mediation is not fixed, nor finite, nor indeed necessarily accurate. Over time, practicing mediators may find themselves with 'burning questions' that can only be answered through research.

There exists a myth about research that it is the preserve of an elite, and in some way disconnected from the real world. The reality is that we all conduct research all of the time. Each of us possesses a set of schemas about the world and we constantly seek evidence to confirm or alter those schemas. McLeod made the observation that a counselling therapy session could represent a piece of research. The same argument could apply to mediation.

[A mediation session] .... involves a piecing together of information and understandings, followed by testing the validity of conclusions and actions based on that shared knowing. Over dozens of clients and bundreds of sessions we build up our own theories of what different types of client are like and what is effective with them. These personal theories almost always have some connection to 'official' theories, but retain an idiosyncratic element originating in the unique experiences of the individual [mediator]. (2003: 1) 
In terms of 'official' theories, Wall and Dunne (2012: 219) present a 'Mediation Paradigm' which depicts mediation as existing within a context. The core process is impacted by a range of variables and leads to diverse outcomes for the parties, the mediator, and associated third parties. Each aspect of this paradigm is subject to question, and indeed the purpose of Wall and Dunne's article is to highlight research that has addressed some aspect or other and where the gaps still exist.

Research allows us to clarify, broaden and sometimes change our perspective. Published in accessible formats through appropriate media, it can inform action by providing new ideas and approaches. It can test assumptions, answer questions, and inform decisions. Empirical research can provide evidence of the effectiveness of mediation which in turn can be used to canvass resources or indeed demonstrate accountability for resources already allocated. Research can spread the word about the benefits of mediation and its possible application to new types of disputes. A solid body of empirical research can add credibility to a profession and provide evidence for claims that are made. The findings of research can have implications for policy and practice that can lead to positive change. (McLeod, 2003)

In Ireland, where mediation is increasingly being used (as previously outlined), it is important to have research-based findings on what is happening here and to examine the extent to which international theories have relevance here.

\section{Challenges for researchers}

Conducting research on mediation poses a number of challenges. Mediation is a complex process impacted by the context, the nature of dispute, the mediator, the participants etc. Wall and Dunne's (2012: 319) review of research covers all aspects of the process, outcomes and the context within which mediation takes place. Isolating variables may prove difficult, if not impossible, and boundaries need to be placed around the focus of any empirical study in order to make it feasible to draw valid conclusions.

The confidential nature of the process makes access difficult. Even if the parties agree to allow access to the researcher, his/her presence may alter the dynamic and affect the parties' experience of the process and its outcomes.

Mediation is costly and time-consuming to research and short-term pressure for academic publications may dissuade researchers from choosing this area. Attention also needs to be paid to research methodologies employed. Wall and Kressel (2012) argue that much of the research into mediator style for example is based on self- report methodologies and that mediators don't necessarily do what they say they do. Wall and Dunne (2012: 234) drew several conclusions in their review of a decade of literature. On the positive side they found that research in this area was substantial, spanning 'at least three hundred fifty articles'. However, on the negative side, many of the articles do not report any empirical data, laboratory and field studies are relatively rare, and those that exist often have no control or comparison group.

...scholars are redoing the easy work, overlearning old lessons. Now it is time to move forward with structured research programs in which researchers investigate actual mediations, utilizing comparison groups. (2012: 239)

It is worth noting that none of the research Wall and Dunne refer to is Irish-based. 


\section{Mediation research in Ireland}

Mediation research in Ireland is sparse. Bill Roche and Paul Teague have written extensively on conflict management systems and alternative dispute resolution processes within workplaces in Ireland (Roche and Teague, 2011; Roche and Teague, 2012 (a) and (b); Teague and Roche, 2012; Teague, Roche and Hann, 2012). Whilst mediation is covered in their work, their focus is on whether organisations use mediation or not, rather than exploring the process in detail. The Kennedy Institute for Conflict Intervention hosts a workplace mediation research group that is actively engaged in mediation research, but the group is in its infancy and projects are generally small-scale and under-funded.

The author is a member of that group. Her recent publication, Curran (2014) explored the use of mediation in the resolution of two long-running industrial disputes in Ireland. The author is currently engaged in a research project exploring variation in mediator style/behaviour across four different organisational contexts. Preliminary findings from the research are presented below and will be published in more detail in 2015.

\section{Forthcoming research}

The author's current research explores variation in mediator style across four different organisational contexts. The research focuses on the use of mediation to resolve workplace disputes. The specific contexts included in the research are; two State institutions that offer a mediation service (the Labour Relations Commission and the Equality Tribunal), one large organisation that has a team of trained internal mediators, and a sample of independent mediators who offer services to a range of organisations on a consultancy basis.

Detailed structured interviews, drawing on themes from the international literature, were conducted with mediators in each context. Mediator interviews were designed to tap into the perspective and experience of individuals and to explore the approach, style and behaviours they typically adopt in mediation sessions. As a central player in the process, the mediator perspective provides an important contribution to research in this area, although the limitations of such self-report methodologies are acknowledged. Subsequent phases of this research will adopt other methodologies such as observation and will explore the perspectives of disputants and third parties.

To date, a detailed analysis has only been conducted on the two State institutions (The Labour Relations Commission (LRC) and the Equality Tribunal (ET)). All of the personnel conducting mediations participated in this research (i.e. six mediators in each institution plus a head of service in each institution). The institutional contexts differ in a number of respects including; the nature of disputes, the referral process, the position of the service within wider institutional offerings, and the enforceability of agreements.

Emerging findings indicate that while considerable differences exist between these institutions the core mediation process adopted is largely similar and reflects the process outlined in Diagram $1(\mathrm{p} 2)$, although mediators will adapt the peripherals to suit the exigencies of the dispute presenting in each case. 
The referral process differs between the contexts. In one case the parties chose to opt-in to the process (or not). In the other case they must chose to opt-out in order to avoid it. At the LRC the informal requirement is that the parties have agreed (at least in principle) to mediation before the LRC mediator makes contact. At the Equality Tribunal, mediation is automatically scheduled once a complaint of discrimination has been made as mediation is the default process used to address such complaints under Irish law.

All of the mediators in both contexts engage in pre-mediation with each party individually, and proceed directly to joint session unless the circumstances make this unfeasible. The mediation process is very expeditious in both contexts, often being completed in one sitting. Follow-up is not routine but may be offered to the parties if the mediator feels necessary, for example if the mediator fears that the agreement may not prove sustainable. Even when offered this follow-up facility is rarely taken up.

The mediators in these institutions have been trained by a small number of external providers advocating a facilitative/problem-solving style. Professional training coupled with 'instinct' and experience is perceived by the mediators to inform their approach. Light of the twelve mediators identified their style as 'facilitative'. 'Reaching agreement' was identified as a top three goal by ten of the mediators. Mediators were asked to identify which of 32 behaviours they would 'typically' apply in mediation. Ten of these 32 behaviours were typically employed by ten of the twelve mediators (Highlighted in bold in Table 1 below).

Table 1 Mediator Behaviours (highlighting common behaviours)

\begin{tabular}{|c|c|}
\hline \multicolumn{2}{|c|}{ MEDIATOR BEHAVIOURS } \\
\hline Explain the process at the outset & Making suggestions \\
\hline Raise the issue of the goal at the outset & Siding (selling one party's case to the other) \\
\hline Agree ground rules at the outset & Asking one side to state other side's position \\
\hline Information gathering & Pointing out the alternatives to a failed \\
\hline Paraphrasing/summarising/reframing & mediation \\
\hline Clarifying & Referring to own experience \\
\hline Naming the feelings expressed by a party & Critically evaluating the suggestions of either party \\
\hline Pressing (urging either party) & Criticising the behaviour of either party \\
\hline Taking the side of either party & Steering towards a preferred solution \\
\hline Using positive reinforcement & Using best/worst case scenarios \\
\hline Advising & Determining the order of issues to be addressed \\
\hline Using humour & Refocusing the parties onto the issue in question \\
\hline Empowering (handing back the issue to parties) & Offering advice when asked \\
\hline Using silence & Raising the issue of an unbalanced agreement \\
\hline Allowing emotional outbursts & Raising legal issues relating to an agreement \\
\hline Cooling (taking the heat out of communication) & \\
\hline Highlighting areas of commonality & \\
\hline Expressing your opinion & \\
\hline
\end{tabular}


Some of the behaviours adopted by the mediators don't fit with a self-declared 'facilitative' mediation style. Five of the six ET mediators, and three of the six LRC mediators, said they typically 'make suggestions' to the parties. Five of the six ET mediators, and four of the six LRC mediators, said they typically 'refer to their own experience'. Three of the six ET mediators, and four of the six LRC mediators, said they typically 'express their own opinion' in mediation. This would suggest that some of the mediators are being somewhat more directive than a purely facilitative style would suggest. This finding lends support to Kochan's suggestion that the term 'mediator style captures mediator behaviour imprecisely' and 'incompletely'. (2012: 392) It also lends support to Charkoudian's suggestion that a valid avenue for research is to ignore style labels altogether and focus on behaviours. (2012: 381) Assuming, as this article suggests, that an objective of research is to inform practice, then avoiding style descriptors that are somewhat ambiguous and subject to interpretation, and focusing instead on clearly specified mediator behaviours, is more likely to provide practitioners with evidence of what works best under what circumstances.

Representatives were allowed in both contexts, be they legal advisors, union officials, family members or friends. None of the mediators objected to the presence of representatives, once their presence was in a support capacity and the disputants were allowed to speak for themselves. Both parties also had to agree to the presence of each other's representatives. Legal advisors appeared more frequently at the Equality Tribunal which is somewhat predictable given the legal basis of the presenting disputes.

Caucusing is used routinely during the process at the discretion of the mediator, who will always caucus with both parties. There are very few circumstances in which the mediator will call a halt to proceedings but these include a perceived incapacity of a party to engage or a belief that either party is using the process to gather information for a subsequent adjudicative process. While an apology often forms part of the expectations/demands of one of the parties, and while a spontaneous genuine apology is very rare, the mediators use their skills to ensure that this does not prove an impediment to the process and a form of words can be found that satisfies the need for apology.

Mediated agreements at the Equality Tribunal are legally enforceable while those at the Labour relations Commission are not. It is logical to assume that disputants are more likely to adhere to a binding agreement. The proposed enforceability of mediated agreements under the Workplace Relations Bill (Section 39(6)) is therefore a welcome development.

Further publications on the findings from this research, covering all four research sites, will be forthcoming in 2015/16. Even at this early stage there are some observations that can be made about the value of this work. Very little research is being conducted on workplace mediation in Ireland so this research begins to address that gap. The methodology, of exploring mediator behaviour across different contexts, was recommended by Kochan as a fruitful 'systems' based avenue for progressing knowledge in this field.

.... comparative observational studies that either hold constant context and design and vary mediator style or observe mediator style in varying contexts or systems would provide the variation across cases and mediators needed to sort out whether mediators vary their style or have personal styles they apply across cases regardless of case-specific circumstances. (2012: 393) 
The preliminary findings presented here refer to the two State-funded providers of workplace mediation in Ireland. Coincidentally, and somewhat fortuitously, these two mediation services are in the process of being merged under a broad-scale reform of State institutions in Ireland. This research provides mediators in these contexts with an understanding of what their colleagues 'do' in mediation, what is perceived to work well, and what is best avoided. It provides mediators with ideas and approaches that they may wish to consider. The research report, containing recommendations, has been provided to senior personnel with responsibility for managing the new merged service. The report provides evidence of the effectiveness of both services as they currently operate. As stated earlier, this type of evidence can be used to either canvass or justify resource allocation. This may prove particularly useful in the current context of reform and demonstrates the value of applied research. As already mentioned, focusing specifically on mediator behaviours, rather than generic styles, is likely to provide practicing mediators with practical ideas about what works and what could be done differently to develop their repertoire.

\section{Conclusions}

This article set out to make a case for the importance of research in informing workplace mediation practice in Ireland and the need for more research in this area. Conducting research is a challenging, time-consuming, and costly endeavour and there is a need to develop a critical mass of academics and practitioners willing to contribute to the body of knowledge. The Kennedy Institute for Conflict Intervention seems a natural home for the support and dissemination of this work and efforts are on-going by researchers within the Institute to begin to bridge the research-practice divide.

No single research study has much meaning in isolation. Research studies provide the individual pieces that fit together to create the complex mosaic of the literature on a topic. Research can be viewed as a form of collective knowing that reflects the best efforts of a community to arrive at some level of agreement about how best to proceed in relation to practical concerns. (McLeod, 2013:3)

\section{Acknowledgements}

The author would like to acknowledge Dr Mary Quinn for her helpful comments on drafts of this article. The author would also like to acknowledge the assistance and support of the Labour Relations Commission and Equality Tribunal, and the on- going support of the Edward Kennedy Institute for Conflict Intervention. Finally, thanks are due to the mediators who participated in the research referred to in this article and gave so generously of their time andperspectives. 


\section{References}

Charkoudian, L. (2012) 'Just my Style: The Practical, Ethical, and Empirical Dangers of the Lack of Consensus about Definitions of Mediation Styles' Negotiation and Conflict Management Research, Vol. 5(4), p367-383

Curran, D. (2012) 'The role of mediation in the resolution of two industrial disputes in Ireland: towards a theoretical understanding', Employee Relations, Vol. 36(5), 496-515

Fox, A. (1973) 'Industrial Relations: A Social Critique of Pluralist Ideology', in J. Child (ed.) Man and Organisation. London: Allen \& Unwin

Industrial Relations News (IRN) The Growing Importance of Workplace Mediation in Ireland, Kyran Fitzgerald, IRN 20 - 28/05/2014

Katz, N. H. and Flynn, T. F. (2013) 'Understanding Conflict Management Systems and Strategies in the Workplace: A Pilot Study', Conflict Resolution Quarterly, Vol. 30(4), 393-410,

Kenny, T. (2014) 'Developing the Conversation about Workplace Mediation', The Journal of Mediation \& Applied Conflict Analysis, Vol 1(1)

Kochan, T. A. (2012) 'Commentary 2, special edition of Negotiation and Conflict Management Research, Vol. 5(4) 392-395

Lang, M. (2000) 'Becoming Reflective Practitioners', Mediate.com

www.mediate.com//articles/reflect.cfm

Mediation Bill http://www.justice.ie/en/JELR/MedBillGSFinal.pdf/Files/MedBillGSFinal.pdf

McCleod J. (2003) Doing Counselling Research, $2^{\text {nd }}$ Edition, Sage Publications Limited

Roche, W. K. and Teague, P. (2011) 'Firms and Innovative Conflict Management Systems in Ireland', British Journal of Industrial Relations, 49:3 September 2011, 436-459

Roche, W. K. and Teague, P. (2012: a) 'The Growing Importance of Workplace ADR', The International Journal of Human Resource Management', 23:3, 447-458

Roche, W. K. and Teague, P. (2012: b) 'Human resource management and ADR practices in Ireland', The International Journal of Human Resource Management, 23:3, 528-549

Rose, E. (2001) Employment Relations, Essex: Financial Times/Prentice Hall

Salamon, M. (2000) Industrial Relations: Theory and Practice (4 ${ }^{\text {th }}$ edn.), Essex: Financial Times/Prentice Hall Schaefer, L. F. (2014) 'Dispute Resolution Continuum', http:/ /winwinhr.com/the- continuum-ofdispute-resolution-in-the-workplace/

Teague, P. and Roche, W. K. (2012) 'Line managers and the management of workplace conflict: evidence from Ireland', Human Resource Management Journal, 22: 3, 235-251Teague, P., W. Roche \& D. Hann (2012) 'The diffusion of alternative dispute resolution practices in Ireland', Economic and Industrial Democracy, 1-24 Wall, J. A. and T. C. Dunne (2012) 'Mediation Research: A Current Review', Negotiation Journal, 28(2): $217-244$

Wall, J. and Kressel, K. (2012) 'Research on Mediator Style: A Summary and Some Research Suggestions', Negotiation and Conflict Management research, Volume 5 (4), Pages 403-421Workplace Relations Bill 
http://www.oireachtas.ie/viewdoc.asp?fn=/documents/bills28/bills/2014/7914/document 1.htm

Deirdre Curran, $\mathrm{PhD}$, is employed as an academic at NUI Galway. Deirdre's current area of research interest is workplace mediation. Her most recent academic article explored the use of mediation in the resolution of collective industrial disputes. Deirdre is currently working on a comprehensive research project which explores the factors impacting mediator approach in different institutional contexts. Deirdre is an associate researcher with the Kennedy Institute for Conflict Intervention at NUI Maynooth and she co-ordinates a workplace mediation research group at the Institute. Deirdre can be contacted at Deirdre.curran@nuigalway.ie 